\title{
Functional Differentiation of Adult-Born Neurons along the Septotemporal Axis of the Dentate Gyrus
}

\author{
Melody V. Wu ${ }^{1,2,9}$, Amar Sahay, ${ }^{3,4}$, Ronald S. Duman ${ }^{5,6}$, and René Hen ${ }^{1,2,7,8}$ \\ ${ }^{1}$ Department of Psychiatry, Columbia University, New York, New York 10027 \\ ${ }^{2}$ Division of Integrative Neuroscience, New York State Psychiatric Institute, New York, New York 10032 \\ ${ }^{3}$ Center for Regenerative Medicine and Department of Psychiatry, Massachusetts General Hospital, \\ Boston, Massachusetts 02114 \\ ${ }^{4}$ Harvard Stem Cell Institute and Harvard Medical School, Boston, Massachusetts 02115 \\ ${ }^{5}$ Department of Psychiatry, Yale University, New Haven, Connecticut 06520 \\ ${ }^{6}$ Department of Neurobiology, Yale University, New Haven, Connecticut 06520 \\ ${ }^{7}$ Department of Neuroscience, Columbia University, New York, New York 10027 \\ ${ }^{8}$ Department of Pharmacology, Columbia University, New York, New York 10027 \\ Correspondence: rh95@columbia.edu
}

Over the past several decades, the proliferation and integration of adult-born neurons into existing hippocampal circuitry has been implicated in a wide range of behaviors, including novelty recognition, pattern separation, spatial learning, anxiety behaviors, and antidepressant response. In this review, we suggest that the diversity in behavioral requirements for new neurons may be partly caused by separate functional roles of individual neurogenic niches. Growing evidence shows that the hippocampal formation can be compartmentalized not only along the classic trisynaptic circuit, but also along a longitudinal septotemporal axis. We suggest that subpopulations of hippocampal adult-born neurons may be specialized for distinct mnemonic- or mood-related behavioral tasks. We will examine the literature supporting a functional and anatomical dissociation of the hippocampus along the longitudinal axis and discuss techniques to functionally dissect the roles of adult-born hippocampal neurons in these distinct subregions.

Since the presence of dividing cells in the Smostly postmitotic adult brain was first described (Altman and Das 1965), the generation of new neurons in adulthood has been proposed to be involved in a variety of behaviors (Doetsch and Hen 2005; Becker and Wojtowicz 2007; Sa- hay and Hen 2007; Deng et al. 2010; Ming and Song 2011; Miller and Hen 2014). Adult neurogenesis in the healthy mammalian brain is consistently seen in the subventricular zone (SVZ) of the lateral ventricles and the subgranular zone (SGZ) of the hippocampal dentate gyrus

${ }^{9}$ Current address: Cold Spring Harbor Laboratory, Cold Spring Harbor, New York 11724.

Editors: Fred H. Gage, Gerd Kempermann, and Hongjun Song

Additional Perspectives on Neurogenesis available at www.cshperspectives.org

Copyright (C) 2015 Cold Spring Harbor Laboratory Press; all rights reserved; doi: 10.1101/cshperspect.a018978

Cite this article as Cold Spring Harb Perspect Biol 2015;7:a018978 
M.V. Wu et al.

(DG). Recent studies have implicated hippocampal neurogenesis in learning- and memory-related tasks, such as contextual discrimination and spatial navigation and, specifically, in behavioral pattern separation (Clelland et al. 2009; Sahay et al. 2011; Nakashiba et al. 2012; Niibori et al. 2012; see also reviews in Deng et al. 2010; Ming and Song 2011; Marin-Burgin and Schinder 2012), but also in some behavioral effects of antidepressants (Santarelli et al. 2003; see also reviews in Sahay and Hen 2007; Kheirbek et al. 2012; Tanti and Belzung 2013). However, the exact role of adult hippocampal neurogenesis in some of these behaviors has been debated as some studies have shown no effects of altering adult neurogenesis on spatial navigation or antidepressant response. Proposed explanations have included differences in the behavioral tasks used to measure cognition or emotion, motivational state of subjects, species differences, or in how neurogenesis is defined, either as proliferation, survival, or differentiation (see reviews in Zhao et al.2008; Aimone et al. 2011; Petrik et al. 2012b; Miller and Hen 2014).

It must also be noted, however, that these hippocampal neurons are not born into a singular structure. Work in the past several decades has shown that the hippocampus can be divided, not only along the classic trisynaptic loop, but also longitudinally along a septotemporal axis. The septal (dorsal in rodents; posterior in primates) and temporal (ventral in rodents; anterior in primates) poles, as well as potential intermediate zones of the hippocampus, have different anatomic connections and electrophysiological properties, express a gradient of molecular markers, and play different functional roles, such as performance in spatial learning tasks and stress responses (see reviews in Moser and Moser 1998; Fanselow and Dong 2010). Consequently, adult-born neurons in the hippocampal DG may also be segregated along this longitudinal axis, and conflicting functional roles for neurogenesis may be a result of attempting to examine hippocampal neurogenesis as a unitary phenomenon. It is possible that there are intrinsic, cell-autonomous differences in adult-born neurons generated at opposite poles of the DG. An alternative, although not mutually exclusive, hypothesis is that progenitor cells are initially identical, but differentiate in a dissimilar manner as a result of integration into distinct network circuitry. We will, therefore, first discuss heterogeneity of the hippocampus along its longitudinal axis before reviewing differences in neurogenesis between the septal and temporal poles of the DG. As these topics have been reviewed extensively elsewhere (Moser and Moser 1998; Deng et al. 2010; Fanselow and Dong 2010; Koehl and Abrous 2011; Samuels and Hen 2011; Kheirbek et al. 2012; Petrik et al. 2012b), we will not try to exhaustively cover all the current literature. Rather, we attempt to gather key studies examining a septotemporal gradient of the hippocampus and hippocampal neurogenesis. We will then suggest possible approaches to examine neurogenesis in specific subregions of the hippocampal DG. Finally, a short section will examine segregation of the DG along its transverse axis.

\section{SEPTOTEMPORAL HETEROGENEITY OF THE HIPPOCAMPUS}

\section{Anatomic Connections}

Although the trisynaptic organization of the hippocampal formation is preserved through the rostrocaudal extent of the brain, the temporal and septal poles of the hippocampus receive afferents from and send efferents to distinct neural nuclei (Fig. 1A) (Witter et al. 1989). Retrograde tracers injected in the septal third of DG reveal afferent connections from the superficial and deep layers of the dorsolateral and caudomedial subdivisions of the entorhinal cortex (EC) (Dolorfo and Amaral 1998). These caudal subnuclei of the EC, in turn, receive projections from the postrhinal and caudal perirhinal cortices (Burwell and Amaral 1998), which are themselves innervated by midline and lateral thalamic nuclei and parietal, somatosensory, and occipital cortices (Deacon et al. 1983; Burwell and Amaral 1998). Efferent projections from the septal hippocampus consist largely of recurrent connections to the EC (Dolorfo and Amaral 1998), as well as projections to the 


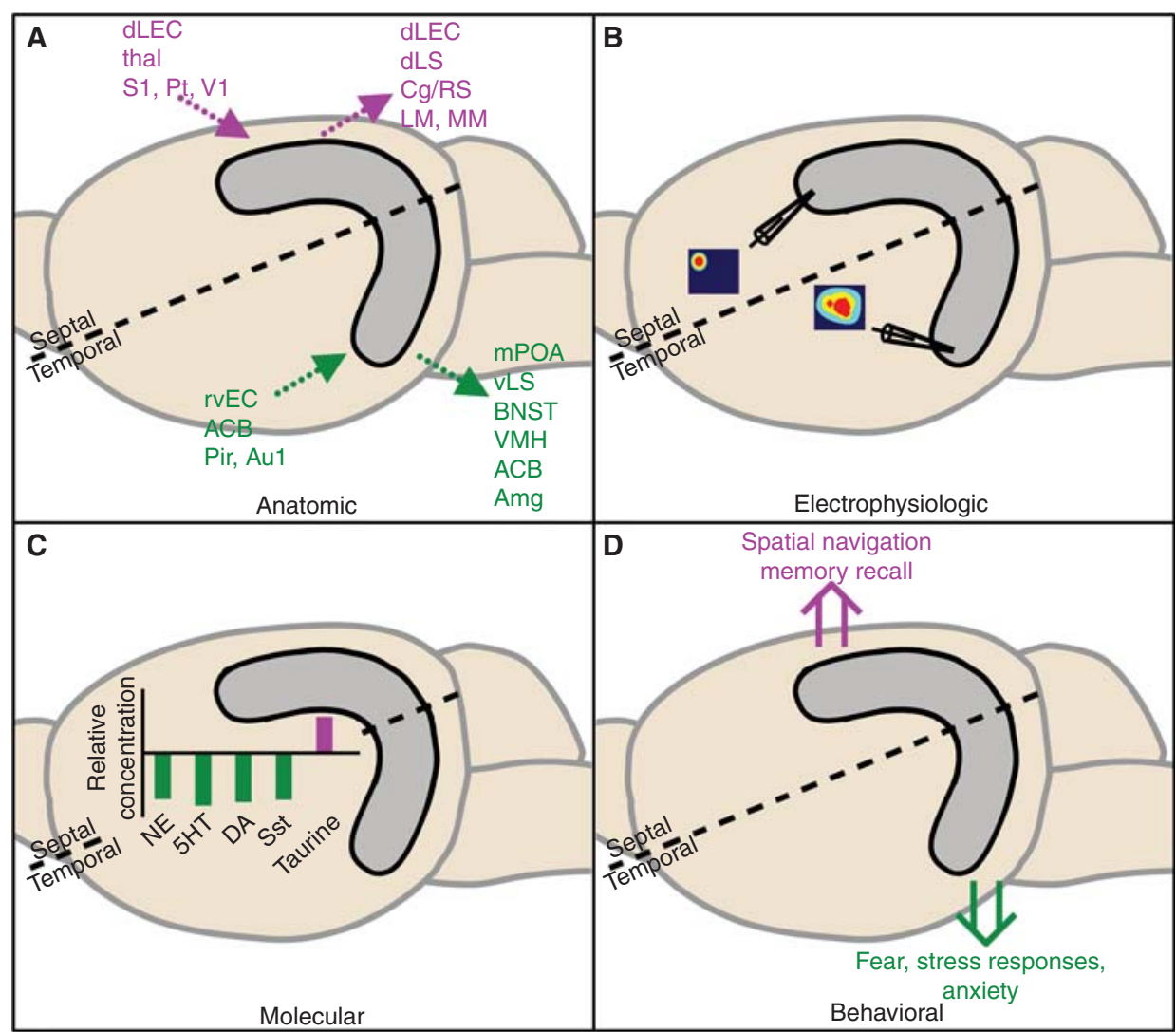

Figure 1. Segregation of the hippocampus along the septotemporal axis. Septal (purple) and temporal (green) subregions of the hippocampus can be dissociated anatomically, electrophysiologically, molecularly, and behaviorally. (A) Dotted arrows represent anatomic efferents and afferents. ACB, Nucleus accumbens; Amg, amygdala; Aul, auditory cortex; BNST, bed nucleus of the stria terminalis; $\mathrm{Cg} / \mathrm{RS}$, cingulate/retrosplenial cortex; dLEC, dorsolateral entorhinal cortex; dLS, dorsolateral septum; LM, lateral mammillary nucleus; $\mathrm{MM}$, medial mammillary nucleus; mPOA, medial preoptic area; Pir, piriform cortex; Pt, parietal cortex; rvEC, rostroventral entorhinal cortex; S1, somatosensory cortex; thal, thalamus; V1, visual cortex; vLS, ventro lateral septum; VMH, ventromedial hypothalamus. $(B)$ Representative spatial place cell firing maps are shown in cartoon form, demonstrating a sharper receptive field in the septal and lower spatial resolution in the temporal hippocampus. $(C)$ Relative levels of norepinephrine (NE), serotonin (5HT), $\gamma$-aminobutyric acid (GABA), glutamate (Glu), dopamine (DA), and somatostatin (Sst) are higher in the temporal hippocampus, whereas taurine is expressed at a higher level in the septal hippocampus. (D) Double arrows depict putative dissociations in behavioral functions along the longitudinal axis.

dorsolateral septum, retrosplenial area of the cingulate, and, via the fimbria and fornix, the mammillary complex (Swanson and Cowan 1977; Cenquizca and Swanson 2007).

The temporal third of the DG receives afferents from the rostroventral EC (Dolorfo and Amaral 1998), which is innervated subcortically by the amygdaloid complex and nucleus accumbens (Vaudano et al. 1991; Burwell and
Amaral 1998). Cortical afferents to the rostroventral EC include the auditory association and piriform cortices (Burwell and Amaral 1998). Projections from the temporal hippocampus, again, include recurrent connections to afferent regions, but also connections to the lateral and medial preoptic area, ventrolateral septum, bed nucleus of the stria terminalis, ventromedial nucleus of the hypothalamus, amygdala, and nu- 
M.V. Wu et al.

cleus accumbens shell (Swanson and Cowan 1977; Pitkanen et al. 2000; Cenquizca and Swanson 2006). This divergence in physical connections suggests that the septal and temporal hippocampus likely participate in separate cognitive and emotional circuits, respectively. It must also be noted, however, that mossy cells do send projections across the longitudinal axis, which possibly provides for communication between the septal and temporal hippocampus (Amaral and Witter 1989; Buckmaster et al. 1996; Blasco-Ibanez and Freund 1997), suggesting that the two regions may not exist in absolute isolation.

\section{Electrophysiological Properties}

In addition to differences in anatomical projections, cells along the longitudinal axis of the hippocampus have distinct electrophysiological properties. Mean amplitude of evoked potentials is higher in slices taken from the temporal pole of the hippocampus at baseline conditions (Gilbert et al. 1985; Maggio and Segal 2007). At higher $\mathrm{K}^{+}$concentrations, epileptiform bursting was induced in all slices, but there was a higher likelihood of burst firing in temporal slices as compared with septal ones (Gilbert et al. 1985; Bragdon et al. 1986). In contrast, the threshold for long-term potentiation (LTP) induction appears to be lower in slices taken from the septal pole of CA1 (Elul 1964). LTP induction is also both larger and longer lasting in septal slices (Maggio and Segal 2007). Additionally, hilar mossy cells in the septal hippocampus have more spontaneous excitatory postsynaptic potentials (EPSPs) with higher maximum amplitude, but lower intrinsic rhythmic bursting than those in the temporal hippocampus (Jinno et al. 2003).

Firing of hippocampal place cells in response to spatial environments also appears to shift along the septotemporal axis (Fig. 1B). When rats were tested along a large linear track, place cell representation changed from a receptive field of $<1 \mathrm{~m}$ at the septal hippocampal pole to $>10 \mathrm{~m}$ in the temporal CA3 (Kjelstrup et al. 2008). Spatial resolution of temporal place cells also appears to be lower when animals are placed in a square arena representation, and the total number of complex spike cells that had place fields dropped from $45 \%$ in the septal to $18 \%$ in the temporal hippocampus (Jung et al. 1994). This change in receptive field seems to parallel an overall shift away from representation of spatial information along the septotemporal axis. Buzsaki and colleagues showed that when rats were placed in either radial arm or zigzag mazes, place cells at the temporal pole of the hippocampus fire in response to reward or goal representations rather than geographical locations (Royer et al. 2010), suggesting that, in addition to spatial representations, cells in the temporal hippocampus may also host nonspatial functions. Cells in the temporal CA3 also appear to be less synchronized as recordings of local field potentials revealed reduced $\theta$ modulation, as well as an overall reduced rhythmicity in this region, further supporting a decline in spatial representation in the temporal region of the hippocampus.

\section{Molecular Markers}

One explanation for these differences in firing patterns could be a gradient of cell types in the hippocampus. Kosaka and colleagues examined inhibitory and excitatory cells along the septotemporal axis of the hippocampus in mice. Staining for GAD67 immunoreactivity revealed a higher numerical density and cell size of inhibitory neurons in the temporal third of the hippocampus compared with the septal third. When separated by laminar subdivision, this septotemporal difference persists in both CA3 and DG, but not CA1 (Jinno et al. 1998). The number of $\gamma$-aminobutyric acid (GABA)ergic interneurons immunoreactive for somatostatin, cholecystokinin, and vasoactive intestinal polypeptide was also higher in the temporal hippocampus (Jinno and Kosaka 2003). Conversely, numerical densities of granule and pyramidal cells expressing GluR2/3 are higher in the septal third of the DG, CA1, and whole hippocampus compared with the temporal third (Jinno and Kosaka 2010). Consequently, examination of GABAergic and glutamatergic neurons in 300$\mu \mathrm{m}$-thick hippocampal slices revealed at least a 
twofold increase in the ratio of inhibitory to excitatory neurons in temporal compared with septal slices. This increased excitatory tone may explain why more cells are active in the septal DG in baseline conditions (Snyder et al. 2009) and may provide for differential network circuitry surrounding adult-born hippocampal cells.

Modulatory neurotransmitters are also distributed along a longitudinal gradient (Fig. 1C). Gage and colleagues showed higher concentrations of norepinephrine (NE) and serotonin (5-HT) in the temporal half of the rat hippocampus (Gage et al. 1978), along with a corresponding increase in the distribution of $\mathrm{NE}$ and 5-HT nerve terminals (Gage and Thompson 1980). This analysis has also been extended to multiple classes of neurotransmitters (Hortnagl et al. 1991). Temporally enriched markers included concentrations of GABA, glutamate, dopamine, noradrenaline and its metabolite 3methoxy-4-hydroxyphenylglycol (MHPG), serotonin and its metabolite 5-hydroxyindoleacetic acid (HIAA), levels of somatostatin, and enzymatic activity of choline acetyltransferase, acetylcholinesterase, and glutamate decarboxylase. Levels of neuropeptide $\mathrm{Y}$ and concentrations of glycine and aspartate were equally distributed across the septotemporal axis. Only concentrations of the amino acid taurine were higher in the septal hippocampus (Hortnagl et al. 1991). The investigators suggest that these results may indicate a denser innervation of the temporal hippocampus raising the possibility that systemic neurotransmitter administration may preferentially alter signaling in the temporal hippocampus. Consistent with this hypothesis, multiple serotonin receptor subtypes (including Htr7, Htr2c, Htr2a, and Htrla) are preferentially expressed in the temporal, compared with septal, CA3 (Htrla is preferentially expressed in the temporal DG, but also in the septal CA1) (Tanaka et al. 2012), in which increased serotonin release has been shown following retrieval of fear memory (Ohmura et al. 2010) or forced swim-induced stress (Yoshitake et al. 2004).

This apparent neurochemical demarcation of hippocampal subregions also suggests that genetic markers may be useful in defining molecular boundaries between the septal and temporal hippocampus. Recent studies have begun to use microarray technology to identify gene expression patterns specific to septal or temporal CA1 (Leonardo et al. 2006; Dong et al. 2009), CA3 (Thompson et al. 2008), and DG (Christensen et al. 2010; Fanselow and Dong 2010). A sample list of candidate genes includes: wolframin, Eph receptor A7 (septal CA1), titin, flavin-containing monooxygenase 1 , protein kinase C delta (septal CA3), adipocyte-specific adhesion molecule, histidine decarboxylase, cocaine, and amphetamine-regulated transcript (septal DG), decorin, neuronatin, synaptotagmin XVII, serotonin receptor $2 \mathrm{C}$, gastrin-releasing peptide (temporal CA1), Rab3b, tissue inhibitor of metalloproteinase 2, and somatostatin receptor 1 (temporal DG). Further characterization of molecular markers needs to be performed, however, especially if these markers are to be used to functionally target-specific subpopulations of the hippocampus and neurogenic niches.

\section{Behavioral Roles}

Functional segregation of the hippocampus as a whole has been studied with double dissociated lesioning strategies in the rat (see reviews in Moser and Moser 1998; Fanselow and Dong 2010). Excitotoxic lesions of either the complete or septal half of the hippocampus result in decreased performance on the T-maze nonmatch to position task, as well as the Morris water maze (Bannerman et al. 2002; Kjelstrup et al. 2002). Behavioral performance in these tasks was spared in animals with temporal lesions. In contrast, temporal, but not septal, hippocampal lesions result in deficits in predator-induced freezing (Phillips and LeDoux 1992), cued fear conditioning (Maren and Holt 2004), and novelty-induced hyponeophagia (Bannerman et al. 2002). Effects of partial lesions on elevated plus maze performance has been equivocal, with some groups showing decreased measures of anxiety only in temporally lesioned animals (Kjelstrup et al. 2002; Trent and Menard 2010), and others demonstrating 
M.V. Wu et al.

deficits resulting from both temporal and septal lesions (Bannerman et al. 2002). Regardless, when taken together, these functional results again complement anatomical and cellular divisions of the hippocampus along its longitudinal axis, suggesting a role for the septal hippocampus in cognitive tasks and the temporal hippocampus in mood- and anxiety-related behaviors (Fig. 1D). Accordingly, behavior in conditioned place preference tasks is impaired in animals with septal hippocampal lesions, but improved in temporally lesioned animals (Ferbinteanu and McDonald 2001). Recent work using optogenetic strategies has, in fact, shown a double dissociation in DG function following acute activation of granule cells. Stimulation of dentate granule cells in the septal hippocampus specifically suppresses contextual encoding and retrieval, likely because of altered activity in downstream dorsal CA3. Conversely, activation of temporal, but not septal, dentate granule cells results in suppression of innate anxiety without altering contextual learning or memory behavior (Kheirbek et al. 2013).

Septotemporal dissociation of the hippocampus has also been examined in humans using functional imaging of hippocampal volumes, with more complex results. Septal hippocampal volume appears to be associated with spatial memory as London taxi drivers, who have an extensive spatial map of the city, have significantly increased gray matter in the septal hippocampus compared with London bus drivers (Maguire et al. 2006). This increase in posterior hippocampal volume, at the expense of the anterior hippocampus, correlates with years of taxi driving and consequent integration of the mental spatial map. Increased volume of the septal hippocampus is also associated with increased recollection memory ability in young adults (Poppenk and Moscovitch 2011). Patients suffering from posttraumatic stress disorder have reduced septal hippocampal volume (Bonne et al. 2008), which the investigators suggest may correlate with maladaptive memory associations commonly observed in the disorder. However, the volume of the septal hippocampus was also seen to be positively associated with degree of psychopathy (Laakso et al. 2001), suggesting that this region may also be implicated in emotional processing. Conversely, the temporal hippocampus appears to be implicated in stress- and mood-related changes as selfreported stress levels and presentation of schizophrenic episodes were both associated with decreased temporal hippocampal volumes (Szeszko et al. 2003, 2006). Older chronic alcoholics also appear to have decreased temporal, but not septal, hippocampal volume (Sullivan et al. 1995), whereas increased exercise correlates with an increase solely in temporal hippocampal volume in older healthy subjects (Erickson et al. 2011). Daily exercise also appeared to correlate with an increase in spatial memory in healthy subjects. Additionally, performance on both contextual (Rajah et al. 2010) and verbal (Hackert et al. 2002) memory tasks has been associated with temporal hippocampus volume. Activation of the temporal hippocampus has also been observed in contextual fear-conditioning tasks (Alvarez et al. 2008). Other studies have suggested that both the temporal and septal regions of the hippocampus are implicated in memory tasks, but that the septal hippocampus is associated with familiarity and the retrieval of information, whereas the temporal hippocampus is preferentially involved in novelty and the encoding of information (Lepage et al. 1998; Strange et al. 1999). Taken together, this suggests multiple degrees of functional specialization along the septotemporal axis of the hippocampus that may be more complex in humans than in rodents.

\section{SEPTOTEMPORAL SEGREGATION OF HIPPOCAMPAL NEUROGENESIS}

As adult-born neurons in the SGZ mature, they migrate along a transverse axis from the hilar border of the granule cell layer (GCL) toward the molecular layer (Kempermann et al. 2003; Li et al. 2009), but appear to stay in the same longitudinal plane. Given the evidence demonstrating a dissociation of the septal and temporal hippocampal poles, it is therefore likely that new neurons may also be similarly segregated along the longitudinal axis of the hippocampus depending on the environment into which they integrate. 
Baseline and Manipulated Levels of Neurogenesis

Studies in multiple rodent species have revealed differences in baseline neurogenesis along the longitudinal axis of the DG. More cells were labeled with 5-bromo- $2^{\prime}$-deoxyuridine (BrdU), a marker of DNA synthesis, in the septal DG one (Dawirs et al. 1998) and two (Ferland et al. 2002) weeks following BrdU administration in the gerbil and mouse, respectively. This may be a result of increased survival of newborn cells rather than changes in proliferation as there is no difference in expression of proliferation cell nuclear antigen (PCNA), an endogenous marker of proliferation (Jinno 2011). Rather, the number of cells expressing doublecortin (DCX), a marker of immature neurons, is higher in the septal DG compared with the temporal. Studies in the rat, however, have been more equivocal. Examination of proliferating cells has revealed either no difference (Banasr et al. 2006; Olariu et al. 2007; Felice et al. 2012), more labeled cells in the temporal DG (Silva et al. 2006), or increased proliferation in the septal DG (Snyder et al. 2009). In contrast to mice, survival of new neurons in rats appears to be equivalent across the septotemporal axis (Banasr et al. 2006; Felice et al. 2012; Snyder et al. 2012). It is possible that these discrepancies are caused by species variation, as baseline neurogenesis has previously been shown to depend on mouse strain (Kempermann et al. 1997). An additional caveat is a lack of standardized boundaries of septal and temporal subdivisions of the DG. Bisection of the DG was performed relative to the third ventricle (Silva et al. 2006), thalamus (Ferland et al. 2002), interaural line (Banasr et al. 2006), or a combination of landmarks (Snyder et al. 2012). Using molecular markers to define septotemporal boundaries may be one way to resolve these differences.

Levels of neurogenesis along the longitudinal axis of the DG can also be differentially manipulated. Although cell proliferation was increased in both the septal and temporal DG of Balb/C mice following $6 \mathrm{wk}$ of environmental enrichment, the number of new neurons was significantly higher only in the septal hippo- campus (Tanti et al. 2012). Conversely, chronic environmental stress or chronic administration of the stress hormone corticosterone appears to preferentially decrease proliferation and neurogenesis in the temporal, but not the septal DG (Jayatissa et al. 2006; Brummelte and Galea 2010; Tanti et al. 2012), although some groups have reported impaired neurogenesis in both the temporal and septal hippocampus (Rainer et al. 2011; Nollet et al. 2012). Interestingly, recent work has shown that acute stress increases the number of proliferating cells in the septal, but not temporal, DG via increased astrocytic fibroblast growth factor (FGF)-2 secretion (Kirby et al. 2013), which the investigators suggest may indicate a beneficial response to acute stress, conferring cognitive plasticity.

Regional differences following pharmacologic induction of neurogenesis have also been reported. LTP (Bruel-Jungerman et al. 2006) and seizures (Parent and Lowenstein 2002) are known to induce neurogenesis, and administration of the seizure-inducing compound flurothyl leads to increased neurogenesis specifically in the septal DG (Ferland et al. 2002). Septal neurogenesis also appears to be preferentially induced following administration of the neuroleptic haloperidol in gerbils (Dawirs et al. 1998). Neurogenic effects of antidepressants appear to be more ambiguous however (see reviews in Tanti and Belzung 2013). The $\mathrm{GABA}_{\mathrm{B}}$ antagonist CGP52432 preferentially increases proliferation, but not survival, in the temporal DG (Felice et al. 2012), whereas the selective serotonin reuptake inhibitor escitalopram induces proliferation specifically in the septal SGZ (Jayatissa et al. 2006). One explanation may be that neurogenic effects of antidepressants are dependent on whether they are administered in baseline conditions or in the context of prior stress. Although chronic administration of the antidepressant fluoxetine increases both cell proliferation and neurogenesis throughout the septotemporal extent of the DG at baseline (Malberg et al. 2000; Santarelli et al. 2003), fluoxetine appears to induce neurogenesis preferentially in the temporal DG following unpredictable chronic mild stress (Tanti et al. 2012). Similarly, agomelatine, a combined melatonin 
M.V. Wu et al.

receptor agonist and serotonin $2 \mathrm{C}$ receptor antagonist, increases dendritic maturation across the septotemporal axis of the DG at baseline conditions in the mouse, but appears to have a temporal-specific effect following chronic corticosterone administration (Rainer et al. 2011). Taken together, these studies suggest that behavioral manipulations may differentially alter levels of adult neurogenesis in the septal or temporal DG depending on how the manipulation may have changed the molecular landscape and/or functional roles of the local surrounding hippocampal network.

\section{Circuit-Mediated Maturation of Immature Neurons}

Newborn neurons in the DG have unique electrophysiological properties. As adult-born neurons mature and integrate into the existing DG circuitry, they are more easily excitable and, as in the developing hippocampus, can be excited by GABA inputs (Esposito et al. 2005). The threshold for LTP induction is also lower and amplitude of induced potentiation is higher in immature neurons (Ge et al. 2007). However, expression of immediate early genes, such as Arc, used as markers of cellular activity, cannot be induced in adult-born cells until 2 wk after birth or later (Jessberger and Kempermann 2003). Oncefully mature, adult-born neurons are indistinguishable from developmentally born granule cells (Laplagne et al. 2006; Toni et al. 2008).

Two recent studies have shown that maturation of new neurons depends on the local circuitry, in which the adult-born neurons are located. New neurons in the septal DG start expressing the immediate early gene, Arc, and the neuronal marker, NeuN, earlier than those in the temporal hippocampus (Snyder et al. 2012), suggesting earlier maturation of septal neurons. Schinder and colleagues also showed that new neurons in the septal DG mature at a faster rate than those in the temporal DG (Piatti et al. 2011). Three-week-old cells in the septal hippocampus have a higher spontaneous excitatory postsynaptic current (sEPSC) frequency, characteristic of mature granule cells, compared with temporal cells. These neurons also have a higher spine density and a higher percentage of them express markers of mature neurons at 3 wk of age, although adult-born neurons in the septal and temporal DG are indistinguishable by 8 wk of age. This altered maturation rate appears to be caused by increased electrical activity in the septal DG, which is consistent with the overall decrease in inhibitory tone seen in the septal compared with temporal hippocampus as a whole. However, voluntary exercise, which has been shown to increase proliferation and survival of neural precursor cells (van Praag et al. 2002), led to an increase in the number of active dentate granule cells and faster maturation rate of adult-born cells solely in the temporal DG, although it is possible that this dissociation is a result of a ceiling effect in the septal DG. It will be interesting to determine whether these temporal DG-specific effects on maturation rate extend to other parameters of adult neurogenesis, including proliferation, survival, and differentiation following voluntary exercise.

Taken together, this suggests that the differentiation of new neurons along the longitudinal axis of the hippocampus may be specified by the local environmental network activity or molecular and cellular landscape. However, it is also possible that there are intrinsic differences in the progenitor cells of the two subregions. In the SVZ of the lateral ventricle, for example, adult neural stem cells differentiate according to cell-autonomous factors established in progenitors during perinatal development rather than environmental signals present during neuronal differentiation (Merkle et al. 2007). Surprisingly, although cultured SGZ-derived progenitors differentiate into olfactory or hippocampal neurons when transplanted into the SVZ or SGZ, respectively (Suhonen et al. 1996), SVZderived progenitors differentiate into neurons only when transplanted into the olfactory bulb, and not hippocampus (Herrera et al. 1999), suggesting that both cell-autonomous and environmental factors play a role in the differentiation of adult-born neurons. It will be interesting to examine neuronal differentiation following transplantation of neural stem cells 
from the septal SGZ into the temporal DG and vice versa.

Schinder and colleagues (Piatti et al. 2011) suggest that differences in maturation time may allow for memory encoding along a graded timescale, such that events that occur closer together in time are represented at a more detailed level by adult-born neurons in the septal DG, whereas events that are separated in time are more generally represented by temporal adultborn dentate granule cells (Aimone et al. 2006). This is reminiscent of speculation by $\mathrm{McNau}-$ ghton and colleagues (Jung et al. 1994) that neurons, regardless of age, in the septal hippocampus may encode high-resolution representations of small spaces, whereas temporal hippocampal neurons represent low-resolution information about larger environments. Taken together, this suggests that neurons in the septal hippocampus, whether developmentally or adult-born, may be specialized for more finely tuned representations or tasks, such as, perhaps, pattern separation.

\section{Functional Roles}

Behavioral deficits following ablation of hippocampal adult-born neurons have included both memory- and emotion-related effects, similar to lesion studies. Adult neurogenesis is required for contextual discrimination, spatial memory, and spatial pattern separation (Clelland et al. 2009; Arruda-Carvalho et al. 2011; Sahay et al. 2011; Denny et al. 2012; Nakashiba et al. 2012; Niibori et al. 2012; see Abrous and Wojtowicz 2015 for in-depth discussion). A role for adultborn neurons in relation to emotion was first proposed with the observation that changes in adult neurogenesis correlate with mood-related manipulations in both negative (Gould et al. 1992) and positive directions (Malberg et al. 2000; van Praag et al. 2002) (especially in the temporal DG). However, rather than mediating the etiology of depression- or anxiety-related behavior, adult hippocampal neurogenesis is thought to be required for some behavioral effects of antidepressants (Santarelli et al. 2003; Surget et al. 2008; David et al. 2009; Perera et al. 2011) or for appropriate stress responses in the context of preexisting disorder (Snyder et al. 2012; for review, see Petrik et al. 2012b). Such preexisting conditions could include social pressures as socially stressed nonhuman primates are more likely to become depressed compared with nonstressed controls (Shively and Willard 2012). Some work has also suggested that an individual's social status in a dominance hierarchy is correlated with levels of adult hippocampal neurogenesis (Kozorovitskiy and Gould 2004; Wu et al. 2014). Interestingly, although the number of neural progenitor cells (NPCs) in the DG is unchanged in human patients with major depressive disorder (MDD) compared with controls, NPC number is increased in MDD patients administered antidepressants compared with untreated patients, particularly in the septal DG (Boldrini et al. 2012).

Given the contribution of adult neurogenesis to these divergent tasks, it is likely that specific subpopulations of adult-born neurons mediate distinct behaviors such that adult neurogenesis in the septal DG plays a role in cognitive tasks, whereas adult-born neurons in the temporal DG regulate mood-related behaviors. Alternately, it may be that adult-born neurons do not themselves mediate distinct tasks, but effect differential behaviors by nature of altering the local network circuitry (Burghardt et al. 2012; Lacefield et al. 2012), which is itself functionally dissociated. To wit, recent work has shown an interaction between depressive-like state and performance on neurogenesis-dependent memory tests (Dery et al. 2013; Shelton and Kirwan 2013), indicating that the contribution of adult hippocampal neurogenesis to depression and anxiety disorders may, in fact, be because of deficits in correct emotional responses to appropriate contextual stimuli (Becker and Wojtowicz 2007; Kheirbek et al. 2012). Wojtowicz and colleagues propose that adult neurogenesis provides for "contextual gating," which suggests that differential memory- or moodrelated behavioral roles for these adult-born neurons are simply a result of divergent downstream connections from the septal and temporal hippocampus to cortical and hypothalamic regions, respectively. We have proposed that 
M.V. Wu et al.

impaired encoding functions of the DG, such as pattern separation-completion balances, might result in ineffective gating of downstream circuits subserving fear and stress responses (Kheirbek et al. 2012). Accordingly, recent work has shown that temporary loss of hippocampal neurogenesis in adolescence, although not adulthood, blocks susceptibility to chronic social defeat in adulthood (Kirshenbaum et al. 2014).

In a similar vein, it has been shown that adult-born neurons serve to confer behavioral flexibility in changing environments (Garthe et al. 2009; Burghardt et al. 2012), a process that may modulate either cognition, emotion, or both, depending on whether these neurons are located in the septal or temporal DG. Given the proposed role for differential maturation in high- versus low-resolution representational encoding (Jung et al. 1994; Aimone et al. 2006; Piatti et al. 2011), the loss of contextual encoding or cognitive flexibility in the temporal DG may then lead to more general, long-term behavioral consequences, such as depression or anxiety.

To assess functional contributions of specific subsets of hippocampal adult-born neurons, precise targeting of these subpopulations is critical. As yet, however, few studies have solely targeted neurogenic subpopulations along the septotemporal axis. Perhaps the most straightforward method is via anatomic targeting of new neurons in either the septal or temporal DG. Retroviral vectors preferentially infect dividing cells (van Praag et al. 2002), and retroviral delivery of the inward rectifier Kir2.1 has already been used to selectively silence adultborn neurons (Piatti et al. 2011). Retroviral vectors encoding the cytotoxic subunit of diphtheria toxin (DTA) have been used to ablate human cancer cells (Qiao and Caruso 2002) and can potentially be directed toward adult-born neurons. Stereotactic targeting of these viruses to distinct subregions along the septotemporal gradient of the DG would either silence or ablate adult-born neurons in circumscribed anatomical regions, allowing for behavioral assessment of the functional roles of these neurons. Additionally, recent work has shown that increased survival of new neurons improves performance on certain learning- and memory-related tasks (Sahay et al. 2011). Local injection of retroviral vectors encoding Cre recombinase (Tashiro et al. 2006) in mice expressing a conditional allele of the proapoptotic gene, Bax (Takeuchi et al. 2005), would allow for examination of behavioral consequences of increased survival of subsets of adult-born neurons.

Optogenetic strategies (Zhang et al. 2007) have also been used to examine effects of directed activation of adult-born neurons in the olfactory bulb (Bardy et al. 2010; Alonso et al. 2012). Retroviral injection of the light-gated cation channel channelrhodopsin (ChR2) into the hippocampus has allowed for acute stimulation of adult-born neurons in slice culture (Toni et al. 2008). Optically activated channels could be targeted to dividing cells along the septotemporal axis via stereotaxic injection of retroviral vectors. Alternately, tamoxifen-inducible Cre recombinase under the control of the nestin (Imayoshi et al. 2006; Lagace et al. 2007; Dranovsky et al. 2011) or DCX (Zhang et al. 2010) promoters could be used to drive Cre-dependent opsin expression (Madisen et al. 2012) in neural stem cell or immature neurons, respectively, at precise time points. Implantation of fiber optic light sources along the septotemporal axis of the hippocampus would then allow for acute stimulation or inhibition of discrete subpopulations of new neurons. Indeed, dissociable behavioral effects following optogenetic manipulation of granule cells along the septotemporal DG, regardless of maturity, have recently been shown (Kheirbek et al. 2013).

$\mathrm{X}$-irradiation has also routinely been used to ablate progenitor cells specifically in the SGZ (Santarelli et al. 2003; Raber et al. 2004; Winocur et al. 2006; Surget et al. 2008). Recent technology has been used to precisely direct X-ray beams to areas as small as $0.5 \mathrm{~mm}$ in diameter (Wong et al. 2008; Armour et al. 2010). Using computed tomography to first visualize the brain of individual animals to guide irradiation treatment, two groups have targeted neurogenic niches specifically in the right hippocampus (Ford et al. 2011) or hypothalamus (Lee et al. 2012). We have used X-irradiation to target 
small windows of dividing cells, allowing us to specifically ablate subpopulations of neural stem cells along the septotemporal axis, and have shown a double dissociation wherein adult hippocampal neurogenesis in the septal DG is critical for normal acquisition of a contextual discrimination task, whereas anxiolytic/antidepressant effects of fluoxetine require adult-born neurons in the temporal DG (Wu and Hen 2014).

Additionally, epigenetic mechanisms, which have been implicated in both mnemonic- and mood-related behaviors, are well known to modulate adult hippocampal neurogenesis (see reviews in Hsieh and Eisch 2010; MateusPinheiro et al. 2011; Lv et al. 2013). It will be interesting to examine chromatin marks in microdissected septal or temporal regions of the DG following stressful interventions or memory tasks to determine whether a dissociation exists in epigenetic modifications along the longitudinal axis of the hippocampus. One could also imagine a scenario in which genes implicated in the stress response, such as the glucocorticoid receptor, are actively repressed in the septal but not temporal hippocampus, allowing for region-specific downstream gene expression.

A caveat of these anatomic approaches is that they still depend on arbitrary separations of the hippocampal formation. There are currently no standardized landmarks to divide the hippocampus along its longitudinal axis, and the inherent curvature of the structure makes it difficult to define a single dividing plane (Snyder et al. 2009). One more stringent way to define these boundaries would be to use molecular markers. A necessary first step, therefore, is to characterize the molecular phenotype of adult-born neurons along the longitudinal axis of the DG. Recent work has coupled microarray technology with fluorescent activated cell sorting (FACS) techniques to identify the molecular profile of adult-born neurons (Bracko et al. 2012; Petrik et al. 2012a). Microdissected septal and temporal DG from mice expressing GFP under the control of the nestin promoter in an inducible manner (Lagace et al. 2007; Dranovsky et al. 2011) could be sorted and screened to determine whether distinct expression profiles exist. Candidate genes could then be used to direct expression of Kir2.1 or DTA as above. It is possible that new neurons in the septal or temporal DG are molecularly indistinguishable, and intersectional approaches (Imayoshi et al. 2009) will be required for specific targeting of immature neurons localized in distinct environmental networks.

One potential method to pharmacogenetically silence pools of adult-born neurons would take advantage of the heteromeric chloride channel GluCl $\alpha \beta$ (Lerchner et al. 2007). Coexpression of both $\alpha$ and $\beta$ subunits is required for functional activation of the modified ivermectin-gated channel. Nestin promoter-directed expression of the inducible Cre recombinase (Imayoshi et al. 2006; Lagace et al. 2007; Dranovsky et al. 2011) could be used to drive expression of the GluCl $\alpha$ subunit, preceded by a loxP-flanked stop cassette, in adult-born neurons with temporal control achieved on systemic administration of tamoxifen. By directing expression of the GluCl $\beta$ subunit to either the septal or temporal DG with specific promoters as identified in microarrays, functional channels would then be expressed only in adultborn cells within tissue-specific regions, allowing for acute targeted silencing of these cells with systemically administered ivermectin.

\section{SEGREGATION ALONG THE TRANSVERSE AXIS OF THE DG}

Although we have focused on a septotemporal dissociation of the hippocampus, a transverse segregation between the suprapyramidal blade of the DG, enclosed between areas CA1 and CA3, and the infrapyramidal blade, located on the opposite side of the DG hilus, also exists. Cells in the suprapyramidal, or upper, blade appear to be preferentially activated following exploration of either the Morris water maze (Snyder et al. 2009) or a novel environment (Chawla et al. 2005; Satvat et al. 2012). However, it has also been suggested that the infrapyramidal, or lower, blade is hyperexcitable compared with the suprapyramidal blade and this phenomenon can be enhanced following seizure induction (Scharfman et al. 2002). Consistent with this, 
M.V. Wu et al.

the ratio of inhibitory basket cells to dentate granule cells has also been shown to be higher in the suprapyramidal blade (Seress and Pokorny 1981). Overall, these differences may be attributable to increased plasticity in the suprapyramidal blade as dendrites are longer and harbor a higher density of spines in this blade as compared with the infrapyramidal blade (Desmond and Levy 1985; Claiborne et al. 1990).

Additionally, there appears to be increased adult neurogenesis at baseline in the suprapyramidal compared with the infrapyramidal blade (Ambrogini et al. 2000; Kempermann et al. 2003; Ramirez-Amaya et al. 2006; Dranovsky et al. 2011; Jinno 2011; although, see also Snyder et al. 2009, 2012). This is, again, consistent with increased adult neurogenesis in a subregion with increased local circuit activity. However, it is unclear whether behavioral manipulations, such as environmental enrichment or spatial learning, increase proliferation predominantly in the suprapyramidal (Tashiro et al. 2007) or infrapyramidal blade (Ambrogini et al. 2000). Interestingly, acute administration of cannabinoids leads to both increased cell number and total dendritic length in the infrapyramidal blade (Lawston et al. 2000). Increased neurogenesis in the infrapyramidal blade is also seen following chronic fluoxetine administration (Satvat et al. 2012), which the investigators suggest may account for the dampened effects of fluoxetine seen on spatial learning and memory.

Taken together, this suggests a dissociation of the transverse axis of the DG similar to that seen along the longitudinal axis. However, the literature examining differences between the supra- and infrapyramidal regions of the hippocampus is less extensive, and whether a similar functional dissociation exists such that the suprapyramidal blade of the DG mediates memory-related tasks, whereas the infrapyramidal blade is preferentially involved in anxiety-related behaviors, remains to be determined. There is also likely to be an interaction between the longitudinal and transverse axes as forebrain ischemia induces neurogenesis in both blades of the septal DG, but only in the infrapyramidal blade of the temporal DG (Choi et al. 2003).

\section{CONCLUSION}

Adult-born neurons in the hippocampus are required in multiple behavioral paradigms. Although it is clear that the hippocampus can be segregated into discrete zones with distinct anatomy, physiology, and functions, specialization of hippocampal neurogenic niches has only recently been examined. Potential subpopulations of NPCs will need to be individually defined, characterized, and targeted to fully comprehend the functional role of these neural stem cells.

\section{ACKNOWLEDGMENTS}

A.S. is supported by a U.S. National Institutes of Health Grant 1-R01MH104175, the Ellison Medical Foundation New Scholar in Aging, and a Whitehall Foundation grant. R.S.D. is supported by the National Institute of Mental Health (RO1MH093897 and R37MH45481) and the State of Connecticut, and is a consultant for Taisho, Naurex, and Sunovion. R.H. is supported by the National Institute for Mental Health (R37 MH068542 [MERIT]), the National Institute on Aging (R01 AG043688), the National Institute of Neurological Disorders and Stroke (R01NS081203-01A1), NYSTEM (C029157), and the Hope for Depression Research Foundation (RGA 11-024). R.H. is a consultant for Roche and Lundbeck.

\section{REFERENCES}

${ }^{*}$ Reference is also in this collection.

* Abrous DN, Wojtowicz JM. 2015. Interaction between neurogenesis and hippocampal memory system: New vista. Cold Spring Harb Perspect Biol 7: a018952.

Aimone JB, Wiles J, Gage FH. 2006. Potential role for adult neurogenesis in the encoding of time in new memories. Nat Neurosci 9: 723-727.

Aimone JB, Deng W, Gage FH. 2011. Resolving new memories: A critical look at the dentate gyrus, adult neurogenesis, and pattern separation. Neuron 70: 589-596.

Alonso M, Lepousez G, Sebastien W, Bardy C, Gabellec MM, Torquet N, Lledo PM. 2012. Activation of adult-born neurons facilitates learning and memory. Nat Neurosci 15: 897-904.

Altman J, Das GD. 1965. Autoradiographic and histological evidence of postnatal hippocampal neurogenesis in rats. J Comp Neurol 124: 319-335. 
Alvarez RP, Biggs A, Chen G, Pine DS, Grillon C. 2008 Contextual fear conditioning in humans: Cortical-hippocampal and amygdala contributions. J Neurosci 28: 6211-6219.

Amaral DG, Witter MP. 1989. The three-dimensional organization of the hippocampal formation: A review of anatomical data. Neuroscience 31: 571-591.

Ambrogini P, Cuppini R, Cuppini C, Ciaroni S, Cecchini T, Ferri P, Sartini S, Del Grande P. 2000. Spatial learning affects immature granule cell survival in adult rat dentate gyrus. Neurosci Lett 286: 21-24.

Armour M, Ford E, Iordachita I, Wong J. 2010. CT guidance is needed to achieve reproducible positioning of the mouse head for repeat precision cranial irradiation. $\mathrm{Ra}$ diat Res 173: 119-123.

Arruda-Carvalho M, Sakaguchi M, Akers KG, Josselyn SA, Frankland PW. 2011. Posttraining ablation of adult-generated neurons degrades previously acquired memories. J Neurosci 31: 15113-15127.

Banasr M, Soumier A, Hery M, Mocaer E, Daszuta A. 2006. Agomelatine, a new antidepressant, induces regional changes in hippocampal neurogenesis. Biol Psychiatry 59: 1087-1096.

Bannerman DM, Deacon RM, Offen S, Friswell J, Grubb M, Rawlins JN. 2002. Double dissociation of function within the hippocampus: Spatial memory and hyponeophagia. Behav Neurosci 116: 884-901.

Bardy C, Alonso M, Bouthour W, Lledo PM. 2010. How, when, and where new inhibitory neurons release neurotransmitters in the adult olfactory bulb. J Neurosci $\mathbf{3 0}$ : 17023-17034.

Becker S, Wojtowicz JM. 2007. A model of hippocampal neurogenesis in memory and mood disorders. Trends Cogn Sci 11: 70-76.

Blasco-Ibanez JM, Freund TF. 1997. Distribution, ultrastructure, and connectivity of calretinin-immunoreactive mossy cells of the mouse dentate gyrus. Hippocampus 7: 307-320.

Boldrini M, Hen R, Underwood MD, Rosoklija GB, Dwork AJ, Mann JJ, Arango V. 2012. Hippocampal angiogenesis and progenitor cell proliferation are increased with antidepressant use in major depression. Biol Psychiatry 72: $562-571$.

Bonne O, Vythilingam M, Inagaki M, Wood S, Neumeister A, Nugent AC, Snow J, Luckenbaugh DA, Bain EE, Drevets WC, et al. 2008. Reduced posterior hippocampal volume in posttraumatic stress disorder. J Clin Psychiatry 69: 1087-1091.

Bracko O, Singer T, Aigner S, Knobloch M, Winner B, Ray J, Clemenson GD Jr, Suh H, Couillard-Despres S, Aigner L, et al. 2012. Gene expression profiling of neural stem cells and their neuronal progeny reveals IGF2 as a regulator of adult hippocampal neurogenesis. J Neurosci 32: 33763387.

Bragdon AC, Taylor DM, Wilson WA. 1986. Potassium-induced epileptiform activity in area CA3 varies markedly along the septotemporal axis of the rat hippocampus. Brain Res 378: 169-173.

Bruel-Jungerman E, Davis S, Rampon C, Laroche S. 2006. Long-term potentiation enhances neurogenesis in the adult dentate gyrus. J Neurosci 26: 5888-5893.
Brummelte S, Galea LA. 2010. Chronic high corticosterone reduces neurogenesis in the dentate gyrus of adult male and female rats. Neuroscience 168: 680-690.

Buckmaster PS, Wenzel HJ, Kunkel DD, Schwartzkroin PA. 1996. Axon arbors and synaptic connections of hippocampal mossy cells in the rat in vivo. J Comp Neurol 366: 271-292.

Burghardt NS, Park EH, Hen R, Fenton AA. 2012. Adultborn hippocampal neurons promote cognitive flexibility in mice. Hippocampus 22: 1795-1808.

Burwell RD, Amaral DG. 1998. Perirhinal and postrhinal cortices of the rat: Interconnectivity and connections with the entorhinal cortex. J Comp Neurol 391: 293-321.

Cenquizca LA, Swanson LW. 2006. Analysis of direct hippocampal cortical field CA1 axonal projections to diencephalon in the rat. J Comp Neurol 497: 101-114.

Cenquizca LA, Swanson LW. 2007. Spatial organization of direct hippocampal field $\mathrm{CA} 1$ axonal projections to the rest of the cerebral cortex. Brain Res Rev 56: 1-26.

Chawla MK, Guzowski JF, Ramirez-Amaya V, Lipa P, Hoffman KL, Marriott LK, Worley PF, McNaughton BL, Barnes CA. 2005. Sparse, environmentally selective expression of Arc RNA in the upper blade of the rodent fascia dentata by brief spatial experience. Hippocampus 15: $579-586$.

Choi YS, Lee MY, Sung KW, Jeong SW, Choi JS, Park HJ, Kim ON, Lee SB, Kim SY. 2003. Regional differences in enhanced neurogenesis in the dentate gyrus of adult rats after transient forebrain ischemia. Mol Cells 16: 232-238.

Christensen T, Bisgaard CF, Nielsen HB, Wiborg O. 2010. Transcriptome differentiation along the dorso-ventral axis in laser-captured microdissected rat hippocampal granular cell layer. Neuroscience 170: 731-741.

Claiborne BJ, Amaral DG, Cowan WM. 1990. Quantitative, three-dimensional analysis of granule cell dendrites in the rat dentate gyrus. J Comp Neurol 302: 206-219.

Clelland CD, Choi M, Romberg C, Clemenson GD Jr, Fragniere A, Tyers P, Jessberger S, Saksida LM, Barker RA, Gage FH, et al. 2009. A functional role for adult hippocampal neurogenesis in spatial pattern separation. Science 325: 210-213.

David DJ, Samuels BA, Rainer Q, Wang JW, Marsteller D, Mendez I, Drew M, Craig DA, Guiard BP, Guilloux JP, et al. 2009. Neurogenesis-dependent and -independent effects of fluoxetine in an animal model of anxiety/depression. Neuron 62: 479-493.

Dawirs RR, Hildebrandt K, Teuchert-Noodt G. 1998. Adult treatment with haloperidol increases dentate granule cell proliferation in the gerbil hippocampus. J Neural Transm 105: 317-327.

Deacon TW, Eichenbaum H, Rosenberg P, Eckmann KW. 1983. Afferent connections of the perirhinal cortex in the rat. J Comp Neurol 220: 168-190.

Deng W, Aimone JB, Gage FH. 2010. New neurons and new memories: How does adult hippocampal neurogenesis affect learning and memory? Nat Rev Neurosci 11: 339350.

Denny CA, Burghardt NS, Schachter DM, Hen R, Drew MR. 2012. 4- to 6-week-old adult-born hippocampal neurons influence novelty-evoked exploration and contextual fear conditioning. Hippocampus 22: 1188-1201. 
M.V. Wu et al.

Dery N, Pilgrim M, Gibala M, Gillen J, Wojtowicz JM, Macqueen G, Becker S. 2013. Adult hippocampal neurogenesis reduces memory interference in humans: Opposing effects of aerobic exercise and depression. Front Neurosci 7: 66.

Desmond NL, Levy WB. 1985. Granule cell dendritic spine density in the rat hippocampus varies with spine shape and location. Neurosci Lett 54: 219-224.

Doetsch F, Hen R. 2005. Young and excitable: The function of new neurons in the adult mammalian brain. Curr Opin Neurobiol 15: 121-128.

Dolorfo CL, Amaral DG. 1998. Entorhinal cortex of the rat: Topographic organization of the cells of origin of the perforant path projection to the dentate gyrus. J Comp Neurol 398: 25-48.

Dong HW, Swanson LW, Chen L, Fanselow MS, Toga AW. 2009. Genomic-anatomic evidence for distinct functional domains in hippocampal field CA1. Proc Natl Acad Sci 106: 11794-11799.

Dranovsky A, Picchini AM, Moadel T, Sisti AC, Yamada A, Kimura S, Leonardo ED, Hen R. 2011. Experience dictates stem cell fate in the adult hippocampus. Neuron 70: 908-923.

Elul R. 1964. Regional differences in the hippocampus of the cat. I: Specific discharge patterns of the dorsal and ventral hippocampus and their role in generalized seizures. Electroencephalogr Clin Neurophysiol 16: 470-488.

Erickson KI, Voss MW, Prakash RS, Basak C, Szabo A, Chaddock L, Kim JS, Heo S, Alves H, White SM, et al. 2011. Exercise training increases size of hippocampus and improves memory. Proc Natl Acad Sci 108: 3017-3022.

Esposito MS, Piatti VC, Laplagne DA, Morgenstern NA, Ferrari CC, Pitossi FJ, Schinder AF. 2005. Neuronal differentiation in the adult hippocampus recapitulates embryonic development. J Neurosci 25: 10074-10086.

Fanselow MS, Dong HW. 2010. Are the dorsal and ventral hippocampus functionally distinct structures? Neuron 65: 7-19.

Felice D, O’Leary OF, Pizzo RC, Cryan JF. 2012. Blockade of the $\mathrm{GABA}_{\mathrm{B}}$ receptor increases neurogenesis in the ventral but not dorsal adult hippocampus: Relevance to antidepressant action. Neuropharmacology 63: 1380-1388.

Ferbinteanu J, McDonald RJ. 2001. Dorsal/ventral hippocampus, fornix, and conditioned place preference. Hippocampus 11: 187-200.

Ferland RJ, Gross RA, Applegate CD. 2002. Differences in hippocampal mitotic activity within the dorsal and ventral hippocampus following flurothyl seizures in mice. Neurosci Lett 332: 131-135.

Ford EC, Achanta P, Purger D, Armour M, Reyes J, Fong J, Kleinberg L, Redmond K, Wong J, Jang MH, et al. 2011. Localized CT-guided irradiation inhibits neurogenesis in specific regions of the adult mouse brain. Radiat Res 175: 774-783.

Gage FH, Thompson RG. 1980. Differential distribution of norepinephrine and serotonin along the dorsal-ventral axis of the hippocampal formation. Brain Res Bull 5: $771-773$.

Gage FH, Thompson RG, Valdes JJ. 1978. Endogenous norepinephrine and serotonin within the hippocampal for- mation during the development and recovery from septal hyperreactivity. Pharmacol Biochem Behav 9: 359-367.

Garthe A, Behr J, Kempermann G. 2009. Adult-generated hippocampal neurons allow the flexible use of spatially precise learning strategies. PLoS ONE 4: e5464.

Ge S, Yang CH, Hsu KS, Ming GL, Song H. 2007. A critical period for enhanced synaptic plasticity in newly generated neurons of the adult brain. Neuron 54: 559-566.

Gilbert M, Racine RJ, Smith GK. 1985. Epileptiform burst responses in ventral vs dorsal hippocampal slices. Brain Res 361: 389-391.

Gould E, Cameron HA, Daniels DC, Woolley CS, McEwen BS. 1992. Adrenal hormones suppress cell division in the adult rat dentate gyrus. J Neurosci 12: 3642-3650.

Hackert VH, den Heijer T, Oudkerk M, Koudstaal PJ, Hofman A, Breteler MM. 2002. Hippocampal head size associated with verbal memory performance in nondemented elderly. Neuroimage 17: 1365-1372.

Herrera DG, Garcia-Verdugo JM, Alvarez-Buylla A. 1999. Adult-derived neural precursors transplanted into multiple regions in the adult brain. Ann Neurol 46: 867-877.

Hortnagl H, Berger ML, Sperk G, Pifl C. 1991. Regional heterogeneity in the distribution of neurotransmitter markers in the rat hippocampus. Neuroscience 45: 261272.

Hsieh J, Eisch AJ. 2010. Epigenetics, hippocampal neurogenesis, and neuropsychiatric disorders: Unraveling the genome to understand the mind. Neurobiol Dis 39: $73-$ 84 .

Imayoshi I, Ohtsuka T, Metzger D, Chambon P, Kageyama R. 2006. Temporal regulation of Cre recombinase activity in neural stem cells. Genesis 44: 233-238.

Imayoshi I, Sakamoto M, Ohtsuka T, Kageyama R. 2009. Continuous neurogenesis in the adult brain. Dev Growth Differ 51: 379-386.

Jayatissa MN, Bisgaard C, Tingstrom A, Papp M, Wiborg O. 2006. Hippocampal cytogenesis correlates to escitalopram-mediated recovery in a chronic mild stress rat model of depression. Neuropsychopharmacology 31: 2395-2404.

Jessberger S, Kempermann G. 2003. Adult-born hippocampal neurons mature into activity-dependent responsiveness. Eur J Neurosci 18: 2707-2712.

Jinno S. 2011. Topographic differences in adult neurogenesis in the mouse hippocampus: A stereology-based study using endogenous markers. Hippocampus 21: 467-480.

Jinno S, Kosaka T. 2003. Patterns of expression of neuropeptides in GABAergic nonprincipal neurons in the mouse hippocampus: Quantitative analysis with optical disector. J Comp Neurol 461: 333-349.

Jinno S, Kosaka T. 2010. Stereological estimation of numerical densities of glutamatergic principal neurons in the mouse hippocampus. Hippocampus 20: 829-840.

Jinno S, Aika Y, Fukuda T, Kosaka T. 1998. Quantitative analysis of GABAergic neurons in the mouse hippocampus, with optical disector using confocal laser scanning microscope. Brain Res 814: 55-70.

Jinno S, Ishizuka S, Kosaka T. 2003. Ionic currents underlying rhythmic bursting of ventral mossy cells in the developing mouse dentate gyrus. Eur J Neurosci 17: 13381354. 
Jung MW, Wiener SI, McNaughton BL. 1994. Comparison of spatial firing characteristics of units in dorsal and ventral hippocampus of the rat. J Neurosci 14: 7347-7356.

Kempermann G, Kuhn HG, Gage FH. 1997. Genetic influence on neurogenesis in the dentate gyrus of adult mice. Proc Natl Acad Sci 94: 10409-10414.

Kempermann G, Gast D, Kronenberg G, Yamaguchi M, Gage FH. 2003. Early determination and long-term persistence of adult-generated new neurons in the hippocampus of mice. Development 130: 391-399.

Kheirbek MA, Klemenhagen KC, Sahay A, Hen R. 2012. Neurogenesis and generalization: A new approach to stratify and treat anxiety disorders. Nat Neurosci 15: 1613-1620.

Kheirbek MA, Drew LJ, Burghardt NS, Costantini DO, Tannenholz L, Ahmari SE, Zeng H, Fenton AA, Hen R. 2013. Differential control of learning and anxiety along the dorsoventral axis of the dentate gyrus. Neuron 77: 955-968.

Kirby ED, Muroy SE, Sun WG, Covarrubias D, Leong MJ, Barchas LA, Kaufer D. 2013. Acute stress enhances adult rat hippocampal neurogenesis and activation of newborn neurons via secreted astrocytic FGF2. eLife 2: e00362.

Kirshenbaum GS, Lieberman SR, Briner TJ, Leonardo ED, Dranovsky A. 2014. Adolescent but not adult-born neurons are critical for susceptibility to chronic social defeat. Front Behav Neurosci 8: 289.

Kjelstrup KG, Tuvnes FA, Steffenach HA, Murison R, Moser EI, Moser MB. 2002. Reduced fear expression after lesions of the ventral hippocampus. Proc Natl Acad Sci 99: 10825-10830.

Kjelstrup KB, Solstad T, Brun VH, Hafting T, Leutgeb S, Witter MP, Moser EI, Moser MB. 2008. Finite scale of spatial representation in the hippocampus. Science 321: $140-143$.

Koehl M, Abrous DN. 2011. A new chapter in the field of memory: Adult hippocampal neurogenesis. Eur J Neurosci 33: 1101-1114.

Kozorovitskiy Y, Gould E. 2004. Dominance hierarchy influences adult neurogenesis in the dentate gyrus. J Neurosci 24: 6755-6759.

Laakso MP, Vaurio O, Koivisto E, Savolainen L, Eronen M, Aronen HJ, Hakola P, Repo E, Soininen H, Tiihonen J. 2001. Psychopathy and the posterior hippocampus. Behav Brain Res 118: 187-193.

Lacefield CO, Itskov V, Reardon T, Hen R, Gordon JA. 2012. Effects of adult-generated granule cells on coordinated network activity in the dentate gyrus. Hippocampus 22: 106-116.

Lagace DC, Whitman MC, Noonan MA, Ables JL, DeCarolis NA, Arguello AA, Donovan MH, Fischer SJ, Farnbauch LA, Beech RD, et al. 2007. Dynamic contribution of nestin-expressing stem cells to adult neurogenesis. J Neurosci 27: $12623-12629$.

Laplagne DA, Esposito MS, Piatti VC, Morgenstern NA, Zhao C, van Praag H, Gage FH, Schinder AF. 2006. Functional convergence of neurons generated in the developing and adult hippocampus. PLoS Biol 4: e409.

Lawston J, Borella A, Robinson JK, Whitaker-Azmitia PM. 2000. Changes in hippocampal morphology following chronic treatment with the synthetic cannabinoid WIN 55,212-2. Brain Res 877: 407-410.

Lee DA, Bedont JL, Pak T, Wang H, Song J, Miranda-Angulo A, Takiar V, Charubhumi V, Balordi F, Takebayashi H, et al. 2012. Tanycytes of the hypothalamic median eminence form a diet-responsive neurogenic niche. $\mathrm{Nat} \mathrm{Neu}$ rosci 15: 700-702.

Leonardo ED, Richardson-Jones JW, Sibille E, Kottman A, Hen R. 2006. Molecular heterogeneity along the dorsal-ventral axis of the murine hippocampal CA1 field: A microarray analysis of gene expression. Neuroscience 137: 177-186.

Lepage M, Habib R, Tulving E. 1998. Hippocampal PET activations of memory encoding and retrieval: The HIPER model. Hippocampus 8: 313-322.

Lerchner W, Xiao C, Nashmi R, Slimko EM, van Trigt L, Lester HA, Anderson DJ. 2007. Reversible silencing of neuronal excitability in behaving mice by a genetically targeted, ivermectin-gated Cl-channel. Neuron 54: $35-$ 49.

Li Y, Mu Y, Gage FH. 2009. Development of neural circuits in the adult hippocampus. Curr Top Dev Biol 87: 149-174.

Lv J, Xin Y, Zhou W, Qiu Z. 2013. The epigenetic switches for neural development and psychiatric disorders. J Genet Genomics 40: 339-346.

Madisen L, Mao T, Koch H, Zhuo JM, Berenyi A, Fujisawa S, Hsu YW, Garcia AJ 3rd, Gu X, Zanella S, et al. 2012. A toolbox of Cre-dependent optogenetic transgenic mice for light-induced activation and silencing. Nat Neurosci 15: 793-802.

Maggio N, Segal M. 2007. Unique regulation of long term potentiation in the rat ventral hippocampus. Hippocampus 17: 10-25.

Maguire EA, Woollett K, Spiers HJ. 2006. London taxi drivers and bus drivers: A structural MRI and neuropsychological analysis. Hippocampus 16: 1091-1101.

Malberg JE, Eisch AJ, Nestler EJ, Duman RS. 2000. Chronic antidepressant treatment increases neurogenesis in adult rat hippocampus. J Neurosci 20: 9104-9110.

Maren S, Holt WG. 2004. Hippocampus and Pavlovian fear conditioning in rats: Muscimol infusions into the ventral, but not dorsal, hippocampus impair the acquisition of conditional freezing to an auditory conditional stimulus. Behav Neurosci 118: 97-110.

Marin-Burgin A, Schinder AF. 2012. Requirement of adultborn neurons for hippocampus-dependent learning. Behav Brain Res 227: 391-399.

Mateus-Pinheiro A, Pinto L, Sousa N. 2011. Epigenetic (de)regulation of adult hippocampal neurogenesis: Implications for depression. Clin Epigenet 3: 5 .

Merkle FT, Mirzadeh Z, Alvarez-Buylla A. 2007. Mosaic organization of neural stem cells in the adult brain. Science 317: 381-384.

Miller BR, Hen R. 2014. The current state of the neurogenic theory of depression and anxiety. Curr Opin Neurobiol 30C: $51-58$.

Ming GL, Song H. 2011. Adult neurogenesis in the mammalian brain: Significant answers and significant questions. Neuron 70: 687-702.

Moser MB, Moser EI. 1998. Functional differentiation in the hippocampus. Hippocampus 8: 608-619. 
M.V. Wu et al.

Nakashiba T, Cushman JD, Pelkey KA, Renaudineau S, Buhl DL, McHugh TJ, Rodriguez Barrera V, Chittajallu R, Iwamoto KS, McBain CJ, et al. 2012. Young dentate granule cells mediate pattern separation, whereas old granule cells facilitate pattern completion. Cell 149: 188-201.

Niibori Y, Yu TS, Epp JR, Akers KG, Josselyn SA, Frankland PW. 2012. Suppression of adult neurogenesis impairs population coding of similar contexts in hippocampal CA3 region. Nat Commun 3: 1253.

Nollet M, Gaillard P, Tanti A, Girault V, Belzung C, Leman S. 2012. Neurogenesis-independent antidepressant-like effects on behavior and stress axis response of a dual orexin receptor antagonist in a rodent model of depression. Neuropsychopharmacology 37: 2210-2221.

Ohmura Y, Izumi T, Yamaguchi T, Tsutsui-Kimura I, Yoshida T, Yoshioka M. 2010. The serotonergic projection from the median raphe nucleus to the ventral hippocampus is involved in the retrieval of fear memory through the corticotropin-releasing factor type 2 receptor. Neuropsychopharmacology 35: 1271-1278.

Olariu A, Cleaver KM, Cameron HA. 2007. Decreased neurogenesis in aged rats results from loss of granule cell precursors without lengthening of the cell cycle. J Comp Neurol 501: 659-667.

Parent JM, Lowenstein DH. 2002. Seizure-induced neurogenesis: Are more new neurons good for an adult brain? Prog Brain Res 135: 121-131.

Perera TD, Dwork AJ, Keegan KA, Thirumangalakudi L, Lipira CM, Joyce N, Lange C, Higley JD, Rosoklija G, Hen R, et al. 2011. Necessity of hippocampal neurogenesis for the therapeutic action of antidepressants in adult nonhuman primates. PLoS ONE 6: e17600.

Petrik D, Jiang Y, Birnbaum SG, Powell CM, Kim MS, Hsieh J, Eisch AJ. 2012a. Functional and mechanistic exploration of an adult neurogenesis-promoting small molecule. FASEB J 26: 3148-3162.

Petrik D, Lagace DC, Eisch AJ. 2012b. The neurogenesis hypothesis of affective and anxiety disorders: Are we mistaking the scaffolding for the building? Neuropharmacology 62: 21-34.

Phillips RG, LeDoux JE. 1992. Differential contribution of amygdala and hippocampus to cued and contextual fear conditioning. Behav Neurosci 106: 274-285.

Piatti VC, Davies-Sala MG, Esposito MS, Mongiat LA, Trinchero MF, Schinder AF. 2011. The timing for neuronal maturation in the adult hippocampus is modulated by local network activity. J Neurosci 31: 7715-7728.

Pitkanen A, Pikkarainen M, Nurminen N, Ylinen A. 2000. Reciprocal connections between the amygdala and the hippocampal formation, perirhinal cortex, and postrhinal cortex in rat. A review. Ann NY Acad Sci 911: 369391.

Poppenk J, Moscovitch M. 2011. A hippocampal marker of recollection memory ability among healthy young adults: Contributions of posterior and anterior segments. Neuron 72: 931-937.

Qiao J, Caruso M. 2002. PG13 packaging cells produce recombinant retroviruses carrying a diphtheria toxin mutant which kills cancer cells. J Virol 76: 7343-7348.

Raber J, Rola R, LeFevour A, Morhardt D, Curley J, Mizumatsu S, VandenBerg SR, Fike JR. 2004. Radiation-induced cognitive impairments are associated with changes in indicators of hippocampal neurogenesis. Radiat Res 162: 39-47.

Rainer Q, Xia L, Guilloux JP, Gabriel C, Mocaer E, Hen R, Enhamre E, Gardier AM, David DJ. 2011. Beneficial behavioural and neurogenic effects of agomelatine in a model of depression/anxiety. Int J Neuropsychopharmacol 15: 321-335.

Rajah MN, Kromas M, Han JE, Pruessner JC. 2010. Group differences in anterior hippocampal volume and in the retrieval of spatial and temporal context memory in healthy young versus older adults. Neuropsychologia 48: 4020-4030.

Ramirez-Amaya V, Marrone DF, Gage FH, Worley PF, Barnes CA. 2006. Integration of new neurons into functional neural networks. J Neurosci 26: 12237-12241.

Royer S, Sirota A, Patel J, Buzsaki G. 2010. Distinct representations and $\theta$ dynamics in dorsal and ventral hippocampus. J Neurosci 30: 1777-1787.

Sahay A, Hen R. 2007. Adult hippocampal neurogenesis in depression. Nat Neurosci 10: 1110-1115.

Sahay A, Scobie KN, Hill AS, O'Carroll CM, Kheirbek MA, Burghardt NS, Fenton AA, Dranovsky A, Hen R. 2011. Increasing adult hippocampal neurogenesis is sufficient to improve pattern separation. Nature 472: 466-470.

Samuels BA, Hen R. 2011. Neurogenesis and affective disorders. Eur J Neurosci 33: 1152-1159.

Santarelli L, Saxe M, Gross C, Surget A, Battaglia F, Dulawa S, Weisstaub N, Lee J, Duman R, Arancio O, et al. 2003. Requirement of hippocampal neurogenesis for the behavioral effects of antidepressants. Science 301: 805-809.

Satvat E, Gheidi A, Voll S, Odintsova IV, Marrone DF. 2012. Location is everything: Neurons born during fluoxetine treatment accumulate in regions that do not support spatial learning. Neuropharmacology 62: 1627-1633.

Scharfman HE, Sollas AL, Smith KL, Jackson MB, Goodman JH. 2002. Structural and functional asymmetry in the normal and epileptic rat dentate gyrus. J Comp Neurol 454: 424-439.

Seress L, Pokorny J. 1981. Structure of the granular layer of the rat dentate gyrus. A light microscopic and Golgi study. J Anat 133: 181-195.

Shelton DJ, Kirwan CB. 2013. A possible negative influence of depression on the ability to overcome memory interference. Behav Brain Res 256C: 20-26.

Shively CA, Willard SL. 2012. Behavioral and neurobiological characteristics of social stress versus depression in nonhuman primates. Exp Neurol 233: 87-94.

Silva R, Lu J, Wu Y, Martins L, Almeida OF, Sousa N. 2006. Mapping cellular gains and losses in the postnatal dentate gyrus: Implications for psychiatric disorders. Exp Neurol 200: 321-331.

Snyder JS, Radik R, Wojtowicz JM, Cameron HA. 2009. Anatomical gradients of adult neurogenesis and activity: Young neurons in the ventral dentate gyrus are activated by water maze training. Hippocampus 19: 360-370.

Snyder JS, Ferrante SC, Cameron HA. 2012. Late maturation of adult-born neurons in the temporal dentate gyrus. PLOS ONE 7: e48757.

Strange BA, Fletcher PC, Henson RN, Friston KJ, Dolan RJ. 1999. Segregating the functions of human hippocampus. Proc Natl Acad Sci 96: 4034-4039. 
Suhonen JO, Peterson DA, Ray J, Gage FH. 1996. Differentiation of adult hippocampus-derived progenitors into olfactory neurons in vivo. Nature 383: 624-627.

Sullivan EV, Marsh L, Mathalon DH, Lim KO, Pfefferbaum A. 1995. Anterior hippocampal volume deficits in nonamnesic, aging chronic alcoholics. Alcohol Clin Exp Res 19: $110-122$.

Surget A, Saxe M, Leman S, Ibarguen-Vargas Y, Chalon S, Griebel G, Hen R, Belzung C. 2008. Drug-dependent requirement of hippocampal neurogenesis in a model of depression and of antidepressant reversal. Biol Psychiatry 64: 293-301.

Swanson LW, Cowan WM. 1977. An autoradiographic study of the organization of the efferent connections of the hippocampal formation in the rat. J Comp Neurol 172: $49-84$.

Szeszko PR, Goldberg E, Gunduz-Bruce H, Ashtari M, Robinson D, Malhotra AK, Lencz T, Bates J, Crandall DT, Kane JM, et al. 2003. Smaller anterior hippocampal formation volume in antipsychotic-naive patients with firstepisode schizophrenia. Am J Psychiatry 160: 2190-2197.

Szeszko PR, Betensky JD, Mentschel C, Gunduz-Bruce H, Lencz T, Ashtari M, Malhotra AK, Bilder RM. 2006. Increased stress and smaller anterior hippocampal volume. Neuroreport 17: 1825-1828.

Takeuchi O, Fisher J, Suh H, Harada H, Malynn BA, Korsmeyer SJ. 2005. Essential role of BAX,BAK in B cell homeostasis and prevention of autoimmune disease. Proc Natl Acad Sci 102: 11272-11277.

Tanaka KF, Samuels BA, Hen R. 2012. Serotonin receptor expression along the dorsal-ventral axis of mouse hippocampus. Philos Trans R Soc Lond B Biol Sci 367: $2395-$ 2401.

Tanti A, Belzung C. 2013. Neurogenesis along the septotemporal axis of the hippocampus: Are depression and the action of antidepressants region-specific? Neuroscience 252: 234-252.

Tanti A, Rainer Q, Minier F, Surget A, Belzung C. 2012. Differential environmental regulation of neurogenesis along the septo-temporal axis of the hippocampus. $\mathrm{Neu}$ ropharmacology 63: 374-384.

Tashiro A, Zhao C, Gage FH. 2006. Retrovirus-mediated single-cell gene knockout technique in adult newborn neurons in vivo. Nat Protoc 1: 3049-3055.

Tashiro A, Makino H, Gage FH. 2007. Experience-specific functional modification of the dentate gyrus through adult neurogenesis: A critical period during an immature stage. J Neurosci 27: 3252-3259.

Thompson CL, Pathak SD, Jeromin A, Ng LL, MacPherson CR, Mortrud MT, Cusick A, Riley ZL, Sunkin SM, Bernard A, et al. 2008. Genomic anatomy of the hippocampus. Neuron 60: 1010-1021.
Toni N, Laplagne DA, Zhao C, Lombardi G, Ribak CE, Gage FH, Schinder AF. 2008. Neurons born in the adult dentate gyrus form functional synapses with target cells. Nat Neurosci 11: 901-907.

Trent NL, Menard JL. 2010. The ventral hippocampus and the lateral septum work in tandem to regulate rats' openarm exploration in the elevated plus-maze. Physiol Behav 101: $141-152$.

van Praag H, Schinder AF, Christie BR, Toni N, Palmer TD, Gage FH. 2002. Functional neurogenesis in the adult hippocampus. Nature 415: 1030-1034.

Vaudano E, Legg CR, Glickstein M. 1991. Afferent and efferent connections of temporal association cortex in the rat: A horseradish peroxidase study. Eur J Neurosci 3: 317-330.

Winocur G, Wojtowicz JM, Sekeres M, Snyder JS, Wang S. 2006. Inhibition of neurogenesis interferes with hippocampus-dependent memory function. Hippocampus 16: 296-304.

Witter MP, Groenewegen HJ, Lopes da Silva FH, Lohman AH. 1989. Functional organization of the extrinsic and intrinsic circuitry of the parahippocampal region. Prog Neurobiol 33: 161-253.

Wong J, Armour E, Kazanzides P, Iordachita I, Tryggestad E, Deng H, Matinfar M, Kennedy C, Liu Z, Chan T, et al. 2008. High-resolution, small animal radiation research platform with $\mathrm{x}$-ray tomographic guidance capabilities. Int J Radiat Oncol Biol Phys 71: 1591-1599.

Wu MV, Hen R. 2014. Functional dissociation of adult-born neurons along the dorsoventral axis of the dentate gyrus. Hippocampus 24: 751-761.

Wu MV, Shamy JL, Bedi G, Choi CW, Wall MM, Arango V, Boldrini M, Foltin RW, Hen R. 2014. Impact of social status and antidepressant treatment on neurogenesis in the baboon hippocampus. Neuropsychopharmacology 39: 1861-1871.

Yoshitake T, Wang FH, Kuteeva E, Holmberg K, Yamaguchi M, Crawley JN, Steiner R, Bartfai T, Ogren SO, Hokfelt T, et al. 2004. Enhanced hippocampal noradrenaline and serotonin release in galanin-overexpressing mice after repeated forced swimming test. Proc Natl Acad Sci 101: 354-359.

Zhang F, Aravanis AM, Adamantidis A, de Lecea L, Deisseroth K. 2007. Circuit-breakers: Optical technologies for probing neural signals and systems. Nat Rev Neurosci 8: $577-581$.

Zhang J, Giesert F, Kloos K, Vogt Weisenhorn DM, Aigner L, Wurst W, Couillard-Despres S. 2010. A powerful transgenic tool for fate mapping and functional analysis of newly generated neurons. BMC Neurosci 11: 158.

Zhao C, Deng W, Gage FH. 2008. Mechanisms and functional implications of adult neurogenesis. Cell 132: 645660. 


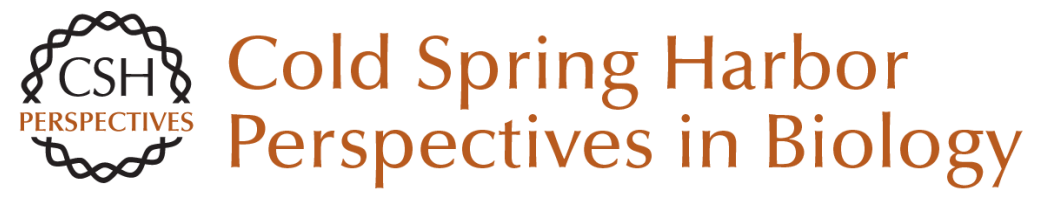

\title{
Functional Differentiation of Adult-Born Neurons along the Septotemporal Axis of the Dentate Gyrus
}

\author{
Melody V. Wu, Amar Sahay, Ronald S. Duman and René Hen \\ Cold Spring Harb Perspect Biol 2015; doi: 10.1101/cshperspect.a018978
}

\section{Subject Collection Neurogenesis}

Adult Neurogenesis and Psychiatric Disorders

Eunchai Kang, Zhexing Wen, Hongjun Song, et al.

Neuronal Circuitry Mechanisms Regulating Adult

Mammalian Neurogenesis Juan Song, Reid H.J. Olsen, Jiaqi Sun, et al.

Neurogenesis in the Developing and Adult Brain

- Similarities and Key Differences

Magdalena Götz, Masato Nakafuku and David Petrik

Genetics and Epigenetics in Adult Neurogenesis Jenny Hsieh and Xinyu Zhao

The Adult Ventricular-Subventricular Zone (V-SVZ) and Olfactory Bulb (OB) Neurogenesis Daniel A. Lim and Arturo Alvarez-Buylla

Diversity of Neural Precursors in the Adult

Mammalian Brain

Michael A. Bonaguidi, Ryan P. Stadel, Daniel A. Berg, et al.

Detection and Phenotypic Characterization of Adult Neurogenesis H. Georg Kuhn, Amelia J. Eisch, Kirsty Spalding, et al.

Maturation and Functional Integration of New Granule Cells into the Adult Hippocampus Nicolas Toni and Alejandro F. Schinder
Adult Olfactory Bulb Neurogenesis

Pierre-Marie Lledo and Matt Valley

Adult Neurogenesis in Fish Julia Ganz and Michael Brand

In Vitro Models for Neurogenesis Hassan Azari and Brent A. Reynolds

Engineering of Adult Neurogenesis and Gliogenesis

Benedikt Berninger and Sebastian Jessberger

Computational Modeling of Adult Neurogenesis James B. Aimone

Control of Adult Neurogenesis by Short-Range Morphogenic-Signaling Molecules Youngshik Choe, Samuel J. Pleasure and Helena Mira

Adult Neurogenesis: An Evolutionary Perspective Gerd Kempermann

Epilepsy and Adult Neurogenesis Sebastian Jessberger and Jack M. Parent

For additional articles in this collection, see http://cshperspectives.cshlp.org/cgi/collection/

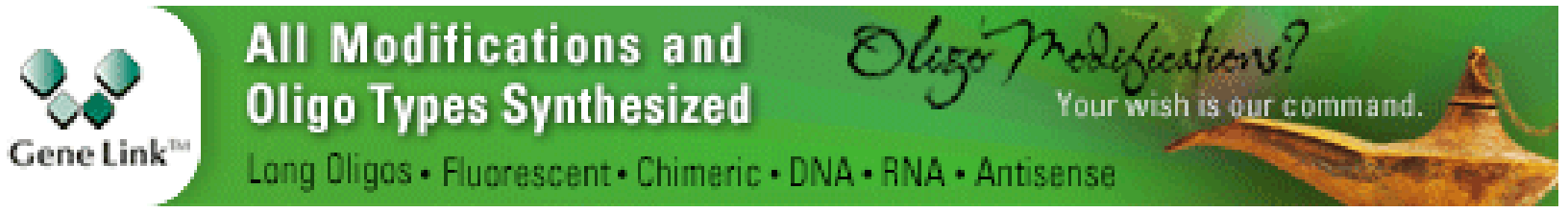


For additional articles in this collection, see http://cshperspectives.cshlp.org/cgi/collection/

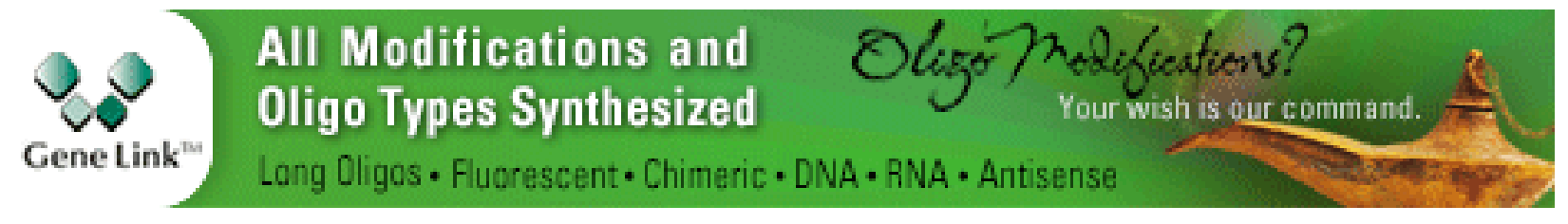

Copyright @ 2015 Cold Spring Harbor Laboratory Press; all rights reserved 